\title{
O Serviço Social e prática pedagógica: a arte como instrumento de intervenção social
}

Social work and teaching practice: art as an instrument of social intervention

Débora Guimarães da Conceição*

\begin{abstract}
Resumo:
Este artigo discute a possibilidade e a potencialidade da arte como instrumento que colabore para uma prática pedagógica crítica e criativa do assistente social, evidenciando o potencial educador da arte como meio para consolidação desta ação. Para isso, são abordados os diferentes sentidos e conotações que a educação pode vir a ter em meio à disputa hegemônica. A discussão abrange o estudo da contribuição do Serviço Social na criação de consensos na sociedade em torno de interesses das classes fundamentais, que pode reforçar a hegemonia vigente ou criar uma contra-hegemonia no cenário da vida social. A potencialidade da arte somada à dimensão pedagógica do Serviço Social, quando construída num sentido de transformação e emancipação dos usuários, pode contribuir para a informação e a promoção de sujeitos mais questionadores da realidade social.
\end{abstract}

Palavras-chave: Prática pedagógica; Assistente social; arte; Emancipação.

\begin{abstract}
:
This article discusses the possibility and the potentiality of the art as an ins trument that collaborates with the pedagogical practice of a creative and analytical social assistant, highlighting the potential educator of the art as a means of consolidating the measure. To accomplish this, the different meanings and connotations that education can come to have in the hegemony dispute will be addressed. The discussion covers the study of the Social Work contribution in the creation of a consensus in the society concerning the interests of the fundamental classes, reinforcing the valid hegemony or creating a counter-hegemony in the social life scenery. The potentiality of the art coupled with the pedagogical dimension of the Social Service may, when constructed in the sense of the transformation and emancipation of the users, contribute to the knowledge and development of individuals more inquisitive of their social reality.
\end{abstract}

Key words: Pedagogical practice; Social assistant; Art; Emancipation .

\footnotetext{
*Assistente Social graduada pela UNIPLI. E-mail deboragconceicao@ig.com.br
} 


\section{Introdução}

Perante tantos desafios postos à profissão, em meio às manife stações da questão social hoje, exige-se dos profissionais cada vez mais competência e criatividade na construção de estratégias para intervenção profissional. Portanto, com o intuito de encarar tais desafios, o eixo de análise deste trabalho volta -se à reflexão sobre a possibilidade e a potencialidade da arte como instrumento que colabore para uma prática crítica e criativa do assistente social, possibilitando que o profissional atinja diferentes objetivos e públicos, graças à magia e ao potencial inerente à arte.

A dimensão pedagógica do Serviço Social está vinculada à intervenção do assistente social na maneira de agir e de pensar da sociedade e aos elementos políticos e culturais da luta pela hegemonia, visto que está inserido nos processos diferenciados de organização e reorganização da cultura. Enquanto isso, a possibilidade de emancipação e humanização inerentes a arte pode oferecer aos sujeitos condições para criticar a situação vivida e redimensioná-la. Desse modo, indaga sobre as contribuições que a arte pode trazer quanto ao caráter pedagógico da prática profissional.

Entende-se, como caminho principal para transformação, a educação que, segundo Gramsci (1999), é o principal meio para que sujeitos acríticos se transformem em sujeitos conscientes. Tal questão será discutida principalmente na primeira parte do texto, a partir de conceitos como educação, ideologia, relações pedagógicas e como esses fatores exercem interferência e contribuem para a construção, solidificação e manutenção de uma dada hegemonia.

Num segundo momento e articulado aos conceitos supracitados, far -se-á o debate sobre o Serviço Social e a essência pedagógica inerente à profissão. Nesse sentido, daremos destaque aos elementos que cooperam para uma prática emancipatória, que contribua para o acesso dos usuários à informação e lhes proporcionem maior participação social, no que diz respeito à luta por seus direitos.

Por fim, a análise incorpora o porquê do uso da arte, sua relação com a prática pedagógica do Serviço Social e uma rápi da reflexão acerca do uso do cinema como instrumento interventivo do assistente social. 


\section{Educação e luta pela hegemonia}

Educação é uma atividade socialmente organizada, controlada pelas estruturas sociais conforme seus interesses. É um aparelho fundamental da superestrutura, condicionada às idéias, juízos, valores e preconceitos (CAVALCANTE, 1984). O conceito de educação, fundamentado em Gramsci $^{1}$, não se limita às relações escolares. Para o autor, a educação constitui o próprio núcleo da hegemonia ${ }^{2}$. Portanto, tem caráter político.

Por seu caráter político, a educação não é ne utra. Na sociedade capitalista, ela pode tanto aderir à ideologia vigente, dissimulando as contradições - caracterizada pela transferência de conhecimentos e valores de uma classe para outra, por meio de diversos aparelhos, com o intuito de ajustar as clas ses dominadas aos interesses da dominante, como também pode buscar superar e desmascarar tal ideologia por meio da resistência à educação dominante, gerando conhecimentos e valores que lhe são próprios. Pode ser responsável pelo aparecimento de uma nova or dem intelectual e moral, que superando o senso comum, possibilite o questionamento e o desenvolvimento de forças para a transformação e superação das contradições da sociedade. Isso ocorre, porque nenhuma ideologia pode dominar inteiramente, havendo no esp aço social a possibilidade de uma correlação de forças, de disputa ideológica. Assim, apesar da prevalência da ideologia dominante, existem espaços de contradição e compete ao educador semear, nesses espaços, elementos de uma nova educação. A educação não é a única responsável pela tarefa de transformação social, mas tem um papel fundamental como instrumento de suma importância na luta entre as classes.

As relações pedagógicas, de acordo com a análise de Rummert (1986), são norteadas por uma determinada ide ologia, que se difunde e se afirma como um processo através do qual uma classe conduz e mantém a unidade do bloco social. Apesar de a

1 Como analisa Buttigieg, J. A (2003).

2 De acordo com a análise de Rummert (1986), a hegemonia (consolidada e estruturada no âmbito da sociedade civil) consiste na capacidade de uma classe subordinar intelectual, cultural e moralmente às demais, através da persua são e da educação. De manter unificado o bloco social através de sua ação no campo das ideologias, da cultura e da moral. É, pois, necessário, que esta classe se apresente capaz de dirigir, de solucionar os problemas da sociedade, de manter articuladas as forças heterogêneas que compõem o bloco social. Para isto, a classe dominante utiliza aparelhos de hegemonia, que de acordo com Rummert(1986) podem ser compreendidos como organizações culturais que movimentam o mundo ideológico, enfim, o conjunto complexo de instituições da sociedade civil em suas mais variadas articulações e subsistemas como por exemplo: a igreja, os meios de comunicação, a organização cultural, dentre outros. 
ideologia dominante mostrar-se sistematizada e revestida de um caráter de universalidade, não representa nem mesmo a expre ssão uniforme das concepções da classe que a elabora, visto que, no interior do bloco dominante também há fracionamentos, correlação de forças. As relações pedagógicas estão eminentemente vinculadas à luta pela hegemonia, ou seja, à busca por direção intel ectual e moral que uma classe, ou frações de classes, imprime ao conjunto da sociedade, mediante processos coercitivos e persuasivos dos quais a ideologia pode ser compreendida como elemento central (ABREU, 2004). Cabe aqui ressaltar como aparelho de hegem onia a arte (instrumento abordado em destaque neste trabalho), haja vista a interpretação que pode ser feita do seu poder de cativar e a possibilidade de formar opinião, de acordo com o objetivo para o qual é direcionada.

Os responsáveis pela tradução e transmissão da hegemonia são os intelectuais. Gramsci (1999) caracteriza-os como "funcionários da superestrutura", visto que atuam no campo da organização e reprodução ideológica, como afirma:

[...] uma massa humana não se 'distingue' e não se tornaria ind ependente 'por si', sem organizar-se (em sentido lato); e não existe organização sem intelectuais, isto é, sem organizadores e dirigentes, sem que o aspecto teórico da ligação teoria-prática se distinga completamente em um estrato de pessoas 'especializadas' na elaboração conceitual e filosófica. (GRAMSCI, 1999, p. 104)

Na concepção de Gramsci (1999), o intelectual orgânico é aquele que dá homogeneidade e consciência ao grupo ao qual se vincula, devendo para isso possuir certa capacidade dirigente e técnica, ser um organizador de massa. Pode atuar tanto a favor da classe trabalhadora como da classe dominante, pois o exercício dessa função diretiva/organizativa pode tomar direci onamentos distintos. Desse modo, ao trabalhar para a classe dominante, tem por função legitimar o domínio, manipulando os meios de comunicação e publicidade, as artes, a educação e a política. Por meios persuasivos, o intelectual orgânico tenta por fim à contestação, buscando fazer parecer universais interesses restritos a determinado grupo, fortalecendo, assim, a hegemonia desta classe. Já quando ligado às forças populares emergentes, como afirma Jesus (1989), o intelectual orgânico entra em cena dada a ne cessidade histórica de superação de uma hegemonia por outra, quando representa não apenas um aliado, um companheiro teórico e artista, 
mas também uma força organicamente ligada ao proletariado em luta contra hegemônica.

A concepção de mundo imposta pela cl asse que detém o poder e, de forma acrítica, absorvida pelo homem é o que se entende por participação passiva, correlacionada com o que Gramsci (1999) chama de "homem -massa" - o que possui consciência fragmentada, que não entende o significado de sua própr ia ação e, conseqüentemente, não age de modo coerente. Por outro lado, o autor traz a dimensão do homem, cuja ação se volta contra a aceitação passiva do que é determinado pela classe dominante: o "homem consciente" que conhece a si mesmo e entende o signi ficado de seus atos, transformando a si e aos outros, que estão envolvidos em seu grupo social, em agente de transformação.

O que motiva a diferença entre essas duas dimensões de homem é que eles vivenciam, de forma distinta, as relações pedagógicas, ou s eja, o conjunto de relações através das quais o homem aprende os valores, costumes, elementos da cultura e demais componentes da concepção de mundo em determinada sociedade.

No entanto, um questionamento fundamental que Gramsci apresenta não se refere somente ao que o homem é e sim, [a] "o que o homem pode se tornar?". O autor afirma que, apesar de assumir uma consciência de mundo sem crítica, o "homem -massa", em contato com indivíduos que ocupam um lugar de transformação na realidade, pode passar da condição de submisso à de consciente e à de participante.

\section{A função pedagógica do assistente social na sociedade capitalista}

A prática profissional do assistente social possui um cunho eminentemente pedagógico. No entanto, como foi visto anteriormente, a prátic a educativa pode servir tanto para manutenção da ordem como para sua transformação. Assim, que tipo de educação vem reproduzindo o Serviço Social na sociedade capitalista contemporânea? Que dimensões visa com essa prática?

Ao atuar sobre questões que dize $m$ respeito à sobrevivência do trabalhador, por meio de serviços sociais previstos em programas, a partir dos quais trabalha nas áreas de saúde, educação, condições habitacionais, dentre outras, o assistente social se insere no processo de reprodução da for ça de trabalho, nas condições materiais. Assim, entende -se que o trabalho do assistente social 
tem também um efeito que não é material, mas é socialmente objetivo. Tem objetividade que não é material, mas é social[...] Tem também efeitos na sociedade como um profissional que incide no campo do conhecimento, dos valores, dos comportamentos, da cultura, que, por sua vez, têm efeitos reais interferindo na vida dos sujeitos (IAMAMOTO, 2005, p.67).

Pode-se dizer que os serviços sociais prestados, previstos e regulados pelo Estado servem de suporte material para uma ação de cunho educativo. Na análise de Barroso e Karmmann (1983), o assistente social controla o uso dos serviços, contribui para agilizá los, informa os outros técnicos da realidade da população e previne tensões sociais. Com isso, o atendimento feito ao trabalhador se estende à sua família, e através de tal atendimento o assistente social interfere na vida privada dos usuários, num processo de reprodução das relações sociais. A dimensão material/ob jetiva da ação profissional é indissociável da dimensão subjetiva.

A função educativa do assistente social concretiza em todos os espaços ocupacionais. $\mathrm{O}$ perfil pedagógico dessa prática advém da intervenção direta desse profissional na maneira de agir e pensar, ou seja, sua ação incide diretamente na formação da cultura. É um elemento constitutivo das relações de hegemonia na sociedade, pois, juntamente com outros profissionais, contribui para a criação de consensos na sociedade em torno de interesses das classes fundamentais, reforçando a hegemonia vigente ou criando uma contra-hegemonia no cenário da vida social. A consciência política e o projeto ético político ao qual o assistente social vem a aderir são o que gera a diferença entre o direcionamento de uma prática que contribua para a manutenção da ordem vigente ou uma prática que coopere para a emancipação dos sujeitos. Observa -se, aqui, que por condições históricas, a burguesia tem mais chances de cooptar o assistente social ao seu projeto político, pois este é um profissional assalariado que necessita vender sua força de trabalho para sobreviver, enquanto a burguesia é a detentora dos meios de produção.

Abreu (2004) menciona que a importação de parâmetros interventivos europeus e norte-americanos pelo Serviço Social, que transplantado de um contexto sócio -histórico para outro sem levar em consideração as particularidades de cada país

representou, sob o ponto de vista das necessidades sociais da classe trabalhadora, uma desarticulação num duplo sentido - histórico-metodológico e histórico e político - contribuindo para aprofundar a dependência e a sujeição do indivíduo que recebe a "ajuda", bem como viabilizar o desenvolvimento também dependente da própria profissão como prática e como teoria.[ABREU, 2004 , p.53] 
Também as alterações realizadas nos currículos das Escolas de Serviço Social constituem um importante fator que tem influenciado o posicionamento político dos assistentes sociais. De acordo com Barroso e Karmmann (1983), a introdução de categorias mais amplas do materialismo dialético nos currículos das escolas levou a uma mudança de visão ao determinar objetivos profissionais e ao introduzir termos como conscientização, organização e mobilização das classes populares, tentando superar as clássicas metas de assistência e promoção, dominantemente integradoras do sistema hegemônico.

No momento histórico em que o Serviço Social se apropria da teoria marxista, o assistente social pode ser, ou se portar como, um intelectual orgânico da classe trabalhadora, podendo contribuir para a organização dessa classe. De acordo com lamamoto e Carvalho (2004), a função educativa dos assistentes sociais integra o amplo processo de elaboração de uma ideologia própria, desenvolvida por essa classe, como elemento constitutivo de uma nova e superior cultura. Supõe compromisso político consciente com o projeto societário das classes subalternas e competências teórico metodológicas e políticas para a identificação e apropriação das reais possibilidades postas pelo movimento social para o redimensionamento da prática profissional no horizonte da luta pela emancipação das referidas classes.

Como já fora visto, o Serviço Social é uma profissão socialmente determinada. Assim, as mudanças ocorridas no seio da profissão - no caso, a busca de uma ruptura com o marco conservador - não são unicamente geradas pela vontade dos profissionais, mas por um contexto sócio-político e econômico que busca a democratização da sociedade brasileira, a descentralização do poder do Estado e a partici pação social de novos sujeitos e movimentos sociais em direção à construção de políticas públicas. Como conseqüência, um conjunto de novas configurações e de demandas para a atuação ganhou lugar no cenário profissional dos assistentes sociais.

A postura histórica assumida pela profissão tem interferido na reprodução da força de trabalho tanto em sua dimensão material como em sua dimensão sócio -política e ideocultural, contribuindo para a defesa dos direitos humanos, da justiça, da liberdade, da equidade e da democracia. As conquistas teórico-práticas e ético-políticas e a busca pelo rompimento com a filosofia conservadora reafirmam um novo perfil profissional, 
competente teórica, técnica e politicamente. Conforme Sarmento (2000), os assistentes sociais devem buscar responder, com ações qualificadas que detectem tendências e possibilidades impulsionadoras de novas ações, projetos e funções, rompendo com atividades rotineiras e burocráticas.

A partir das estratégias educativas, quer seja da pedagogia da ajuda e da participação, que visam a reprodução da lógica capitalista, ou da construção de uma pedagogia emancipatória pelas classes subalternas, a função pedagógica da prática do assistente social está vinculada, na sociedade capitalista, aos processos político s e culturais na luta pela hegemonia, posto que está inserida nos processos diferenciados de organização e reorganização da cultura. Segundo lamamoto (2004), os profissionais contribuem nessa direção à medida que socializam informações que subsidiam a formulação e a gestão de políticas públicas e o acesso a direitos sociais, ao viabilizarem o uso de recursos legais em prol dos interesses da sociedade civil organizada e ao interferirem na gestão e avaliação daquelas políticas, ampliando, assim, o acesso a informação a indivíduos sociais para que possam lutar e interferir na alteração dos rumos da vida em sociedade. A ação educativa do Serviço Social, quando pensada numa perspectiva que desmistifique a ideologia dominante e resgate e sistematize o potencial existente no cotidiano das classes trabalhadoras por meio da crítica ao senso comum, torna-se um novo caminho a ser percorrido na busca pela superação e transformação.

\section{A dimensão pedagógica da arte na intervenção do assistente social}

O uso da arte no Serviço Social deve ser condizente com os objetivos profissionais, ou seja, requer a utilização de uma arte que vise a superação da ordem e das relações de exploração vigentes. Assim, os objetivos profissionais do assistente social, quando voltados para a emancipação dos sujeitos e somados ao potencial educativo da arte, buscam colaborar para a construção de uma nova e superior hegemonia, para a formação de homens mais críticos e conscientes.

Um dos grandes desafios inerentes à profissão hoje é dar conta das múlt iplas expressões da questão social. É apreender as diversas formas que estas expressões assumem na atualidade, as múltiplas formas de pressão social e as formas de resistência (muitas vezes ocultas) dos segmentos majoritários da população. O profissional $p$ recisa de 
capacidade crítica e criativa na utilização dos instrumentos para atingir seus objetivos de maneira mais eficiente ao intervir nessas variadas formas de expressão da questão social.

Exige-se um profissional qualificado, que reforce e amplie a su a competência crítica; não só executivo, mas que pensa, analisa, pesquisa e decifra a realidade. Alimentado por uma atitude investigativa, o exercício profissional cotidiano tem ampliadas as possibilidades de vislumbrar novas alternativas de trabalho nesse momento de profundas alterações na vida em sociedade. O novo perfil que busca construir é de um profissional afinado com a análise dos processos sociais, tanto em dimensões macroscópicas quanto em suas manifestações quotidianas; um profissional criativo e inventivo, capaz de entender o "tempo presente, os homens presentes, a vida presente" e nela atuar, contribuindo, também, para moldar os rumos de sua história. (IAMAMOTO, 2005, p.49)

O surgimento da arte está ligado à função religiosa e ocorre num moment o em que se difundiam arte, ciência e religião, funcionando como auxílio à dominação de um mundo inexplorado. De acordo com Fisher (1987), a função original da arte em muito se diferencia da função da arte em uma sociedade em que a luta de classes se aguça, pois estas recrutam a arte a serviço de seus interesses particulares.

A arte é qualificada como uma das formas de consciência social (MARX apud PEIXOTO, 2003), ou seja, o teórico compreende que é também através da arte que os homens tomam consciência das transformações da base econômica e das alterações que eles promovem na superestrutura da sociedade. A arte não se coloca acima das relações sociais. Ela é inerente a essas relações. É um componente da superestrutura que pode contribuir para distintas funções e utilidades, conforme a interpretação e a posição do artista.

Nota-se, aqui, a relação da arte com a educação: que carregada de uma determinada ideologia, a arte pode tanto servir à manutenção da hegemonia dominante, como pode ter por função a libert ação e a transformação do homem. Para Fisher (1987), a arte pode levar o sujeito a compreender a realidade e transformá -la, pois tem como possibilidade tirar o homem de um estado de fragmentação, conseqüente da divisão do trabalho no modo de produção capi talista e que causa a alienação do homem no/pelo trabalho. Entende-se que a arte pode servir a esse homem como meio de "libertação", como meio de pensar com mais criticidade, sua própria existência, podendo auxiliar o desvendamento da alienação que sofremo s no cotidiano de nossa realidade social. 
Nesse ponto, retornemos ao conceito já apresentado por Gramsci, referente ao homem massa. Devido à sua consciência fragmentada, não tem clareza e entendimento de sua própria ação, não podendo avaliar criticamente sua forma de participação no processo histórico. Todavia, para o autor, é necessário pensar além do que o homem é, ao focar também "o que o homem pode se tornar?".

A função da arte, de acordo com Fisher (1987), concerne sempre ao homem total, capacita o 'Eu' a identificar-se com a vida de outros, capacita -o a incorporar aquilo que ele não é, mas tem possibilidade de ser. Quando utilizada para educar, procurando substituir a conformidade e a alienação pela criticidade a arte pode ser um instrumento potencializador do trabalho do assistente social enquanto intelectual orgânico da classe trabalhadora.

$\mathrm{O}$ artista pode ser um perturbador da ordem estabelecida, à medida que expõe por meio de suas obras, suas reflexões e suas ideologias, assim como quando consegue expor por meio da arte os sentimentos confusos da massa em relação ao momento em que vive. Já os indivíduos podem, no ato de presenciar o novo, aprender uma nova visão de mundo ${ }^{3}$. Entende Lukács (apud PEIXOTO, 2003) em sua concepção da arte como $r$ eflexo da realidade, que esta não deve representar um mecânico espelhamento do real, mas sim captar sua essência com a intenção de possibilitar sua apreensão pela consciência, pois esse processo pode ampliar a consciência dos indivíduos, ao se depararem co m uma realidade inusitada e simultaneamente ampliar -Ihes a autoconsciência ao observarem a si mesmos e ao refletirem sobre seu modo de pensar e agir.

Com a ascensão do sistema capitalista, há uma ruptura entre o trabalho como criação e o trabalho como pro duto dos produtores. O trabalho livre e criador transforma se em trabalho alienado, que objetiva a produção de mais -valia. Como sinaliza Peixoto (2003), a fragmentação provocada pelo capitalismo promove o surgimento de especializações (fragmentos que se transformam em um novo tipo de trabalho), que se estabelecem em todos os campos da atividade produtiva, inclusive na arte.

Refletindo essa ruptura entre criação-produção, a autora qualifica três níveis de arte que passam a coexistir no mundo capitalista: a "arte elitista", que essencialmente

3 Esta nova visão, decerto, é carregada de influência em meio a materialização da ideologia do artista, por isto a essência educativa da arte de poder tanto cooperar para a conformação e manutenção da ordem social, como para construção de uma nova ordem societária. 
propõe-se como atemporal e pura, expressão do sentir e de emoções pessoais, fruto da genialidade do autor; a "arte para as massas", uma arte que padroniza gostos e submete as diferenças a um padrão e a um público médio, caracterizada como indústria cultural; e a "arte popular", que põe sua tônica no consumo não mercantil, cujo valor essencial é a representação e satisfação solidária de desejos coletivos ${ }^{4}$.

Destaca-se aqui que esses níveis de arte não funcionam separadamente, mas determinam-se mutuamente pela relativa intercomunicação que existe entre as classes sociais nas sociedades modernas. A arte pode ter diversos sentidos e conotações na sociedade. A essência a que se propõe pode se constituir num fundamental aparelho mediante ao processo de disputa hegemônica, exercendo um papel ideológico e político nas relações sociais. Tal como a educação, a arte não pode ser neutra, pois sua materialização e constituição envolvem-se com a ordem social e histórica. Além disso, está comprometida com a posição do autor perante a realidade e de seu posicionamento político ante as lutas sociais e, conseqüentemente, do partidarismo ${ }^{5}$ da obra.

De acordo com lamamoto (2005), é necessário pensar as estratégias, táticas e técnicas do trabalho profissional em função das particularidades dos temas que são objeto de estudo e ação do assistente social. É preciso que haja um engajamento entre a perspectiva teórico-metodológica e a realidade, assim como um engajamento político vinculado a uma base técnico-operativa para que seja possível imprimir novos caminhos à profissão. As bases teórico-metodológicas são recursos essenciais que contribuem para iluminar a leitura da realidade e, consequentemente, definir os meios para atuação nesta, descobrir alternativas e possibilidades para o trabalho profissional que sejam condizentes

4 "A classe dominante difunde, por meio da indústria cultural, uma id eologia conforme a sua manutenção no poder, utilizando o vasto alcance de público por esta propiciado para reproduzir a hegemonia e, assim, manter a relação de exploração vigente na sociedade. Apesar de ter um grande aparato tecnológico, é esteticamente empobrecida e, basicamente, sem qualidade humana ou marcada por apelos a emoções rasteiras, difundida ou mesmo imposta em larga escala por aparelhos de comunicação de massa, em especial pelos meios de maior penetração cultural, como o rádio, a televisão e o cinema" (PEIXOTO, 2003 p.82). Apresenta-se como um instrumento educativo, surgindo como uma típica "superestrutura do regime capitalista" usada para fins de controle das consciências. E ainda que assumindo os modos exteriores de uma cultura popular, ao invés de crescerem espontaneamente de baixo são impostos de cima. Em contrapartida, a essência a que se propõe a denominada "arte popular" visa fazer frente às imposições e à massificação imposta pela indústria cultural, preocupa -se com os interesses da classe trabalhadora, com o intuito de clarificação das relações sociais. Seus produtores podem ser considerados intelectuais orgânicos da classe trabalhadora, já que se trata de pertencentes ou consonantes com os objetivos desta.

50 entendimento de partidarismo não se refere a adesão em partido político, mas sim à tomada de posição do artista perante a realidade. 
com o modo de vida, com a forma como os sujeitos vivenciam a questão social. A arte pode ser usada como poderoso instrumento para o enriquecimento da prática profissional, meio pelo qual o As sistente social busca atingir seus objetivos.

O assistente social enquanto intelectual deve informar, fomentar a consciência crítica do usuário, possibilitando o questionamento e a reflexão, além da não aceitação passiva das determinações e ideologias que são impostas pela classe dominante, pois estas propiciariam certa acomodação dos indivíduos a permanecerem como espectadores e não como sujeitos sociais, tornando-os bem mais fáceis de serem manipulados. Conforme a analise de Monteiro e Teixeira (1997), a luta contra a alienação, opressão, preconceito e todas as contradições inerentes à própria existência é constante e contínua, no sentido de as pessoas se perceberem como sujeitos produtivos, que transformam a natureza e humanizam suas vivências.

A reflexão apresentada aqui quanto à atuação do profissional de Serviço Social ligada à arte não tem como finalidade a formação de artistas e nem que o profissional o seja necessariamente (apesar de, como em qualquer prática, haver a necessidade mínima de algum conhecimento específico). Como afirma Souza (2004), pensar em possíveis encaminhamentos para o uso dos recursos da arte em trabalhos sociais requer o estabelecimento de algumas clarificações em torno de suas especificidades e potencialidades.

Silva (2000), ao realizar entrevistas com assistentes sociais para análise da percepção destes no que se refere à potencialidade da arte em projetos de intervenção profissional, aponta algumas visões, tais como:

- A arte vista como instrumento capaz de trazer estímulo ao p otencial criativo e crítico do ser humano, como requalificadora de valores, como criadora de novas formas de vida e de realidades;

- A necessidade da criação de trabalhos ou projetos capazes de propiciar o acesso da população às diversas formas de arte, de mocratizando esse acesso, principalmente às camadas menos favorecidas desse direito, das quais faz parte a maioria dos usuários dos serviços sociais e/ou assistenciais deste país;

- O papel da arte enquanto força que se contrapõe à desumanização, enquanto força em oposição à massificação dos homens; 
- A importância do estímulo do potencial criativo do próprio Serviço Social que caminha rumo à elaboração de ações ou intervenções mais criativas;

- A relevância de se criar, através do trabalho quotidiano do as sistente social, oportunidades que possibilitem o afloramento do potencial criativo dos usuários.

- A arte como meio de operacionalização do acesso e da ampliação dos direitos do cidadão.

O Código de Ética profissional possui 11 princípios fundamentais, de ntre estes é possível mencionar: a ampliação e consolidação da cidadania, opção por um projeto profissional vinculado ao processo de construção de uma nova ordem societária e o compromisso com a qualidade dos serviços prestados à população. Como diz lamamo to (2005), é necessário internalizar o conteúdo do Código de Ética e expressá -lo por meio de ações no cotidiano profissional. Ou seja, o assistente social deve buscar, de maneira qualificada e competente por meio da intervenção profissional, a garantia dos direitos civis, sociais e políticos dos usuários, a socialização de informações e, como intelectual da classe trabalhadora, contribuir por meio dos serviços prestados para construção de uma ordem societária sem dominação/exploração.

\section{O cinema como alterna tiva para o trabalho do assistente social}

O cinema é compreendido por alguns teóricos como a síntese moderna de todas as artes: Arquitetura, Música, Pintura, Escultura, Poesia e Dança. Como já fora visto, a arte não é neutra e, assim, também a produção cin ematográfica é construída conforme a realidade do autor, baseada na concepção de mundo que possui. $\mathrm{O}$ uso do cinema pelo profissional de Serviço Social requer fundamental atenção quanto aos aspectos históricos, psicológicos, sociais e ideológicos que os fil mes podem exercer sobre os usuários, como afirma Leandro (2006). Mais que exibir uma realidade é necessário refletir sobre esta, ou seja, pensar para além do cinema em si é pensar também as experiências e questões que são colocadas em foco.

A imagem é constituída de uma multiplicidade de códigos capazes de produzir efeitos, visões e opiniões, mas que em geral passam despercebidos do espectador, 
gerando nestes um estado de excitação emocional que o torna mais receptivo a influências. Examinar a imagem reque r, além de vê-la e senti-la, é também compreendela como mais que uma ilustração ou comprovação da realidade. Além disso, a arte necessita ser vista como constituinte de um processo analítico, pois ultrapassar o papel do espectador "comum" significa ver al ém do que está aparente. É nesta relação que se insere a prática do profissional, ao fomentar a construção e a percepção do espectador enquanto sujeito histórico crítico.

Essa arte eminentemente coletiva, criadora de recursos de comunicação fantásticos e de grandes proporções foi assumida pela indústria cultural como fonte de divertimento para as massas do mundo burguês, sufocando a função social original a qual se propõe . Os interesses mercadológicos que inundam o cinema, priorizam as produções e cultura $s$ estrangeiras, que pouco se identificam com a realidade brasileira. Por isso, o uso do cinema pelo assistente social requer muitos cuidados para que sua ação não venha a incidir em insucessos profissionais no ponto de vista de seus objetivos, sobretudo educativos, pois o produto dessa industria tende a promover o conformismo e a alienação, o que dificulta a compreensão da necessidade da luta por justiça social e por uma efetiva democracia.

É necessário levar em conta tanto o tema e a época da produção q uanto a visão de mundo do autor. Além disso, é essencial conhecer o público a que se destina a atividade e compreender a visão e os conceitos que possuem para que os objetivos profissionais sejam verdadeiramente alcançados através dessa ação.

Na análise de Guerra (2000), são as finalidades que determinam o modo de atuar e as escolhas por alternativas. A passagem do momento da pré -idealização para a ação propriamente dita requer instrumentalidade e pensar a instrumentalidade do Serviço Social requer pensar que são vastas as possibilidades de intervenção profissional. A capacidade criativa do Assistente Social está em saber adaptar um determinado instrumento às necessidades que lhe são apresentadas em seu cotidiano de trabalho, ou mesmo criar outros capazes de produzir mudanças na realidade social, compreendendo a fundo esta realidade para que o instrumental seja utilizado da maneira mais eficaz possível. Como afirma Prates (2007), 
o uso da arte, ou qualquer estratégia de exposição, não pode prevalecer sobre o que é essencial, o conteúdo aprofundado e problematizado da mensagem orientada para uma finalidade, ou a exposição perde densidade e substância. (PRATES, 2007, p.11)

Os filmes, letras de música, fotos e outros registros são instrumentos importantes que podem ser utilizados para interpretar o real. $\mathrm{O}$ uso do cinema, somado aos objetivos interventivos do profissional, pode colaborar para a construção de indivíduos que superem o imediatismo consequente da alienação e se percebam como ser crítico e consciente de sua historicidade. Para Prates (2007), a arte é uma alternativa para o trabalho do assistente social no que diz respeito à possibilidade de interpretação das expressões dos sujeitos materializados na arte enquanto matéria -prima e também no que se refere ao uso da arte como estratégia pedagógica e de exposição (fundamental para que os sujeitos possam se reconhecer enquanto produtores de suas obras e para que se percebam como sujeitos da história). Assim, o reconhecimento da necessidade de práticas alternativas e de intervenções interdisciplinares é essencial, uma vez que nenhuma área sozinha pode dar conta dos complexos fenômenos sociais existentes no trato dos sujeitos enquanto "homem total".

\section{Considerações finais}

A dimensão pedagógica inerente à profis são Serviço Social e o potencial humanizador da arte, quando construídos num sentido de transformação e emancipação dos usuários, podem contribuir para informação e promoção de sujeitos mais questionadores da realidade social, críticos e coerentes.

O uso da arte enquanto instrumento de trabalho do assistente social pode contribuir para que se atinjam os objetivos profissionais de maneira prática e prazerosa. Contudo, a dinâmica do cotidiano profissional, com grande número de demandas, por vezes contribui para que os profissionais priorizem práticas referentes às necessidades básicas e emergenciais, enquanto as ações voltadas para a educação e desenvolvimento do usuário acabam sendo tratadas como "segundo plano". De acordo com Guerra (2000), a instrumentalidade se materializa à medida que os profissionais utilizam, criam, adequam as condições existentes, transformando -as em meios para a objetivação das 
intencionalidades. Vale ressaltar, também, que converter os objetos naturais em coisas úteis e torná-los instrumentos constituem processo teleológico e necessita de um conhecimento correto das propriedades dos objetos. Por isso, trabalhar a arte como instrumento de intervenção requer um real planejamento e cuidadosa análise quanto aos fins educativos a que a esta se propõe, para que os interesses profissionais sejam verdadeiramente alcançados através desta ação.

Trabalhar num viés transformador é fazer valer e fomentar não só o que o homem é, mas também o que ele pode se tornar. Para isso, o caminho fundamental é a educação, principal meio para a constituição de uma nova e superior hegemonia.

A educação, carregada de ideologia, pode tanto contribuir para a solidificação e manutenção da ordem vigente (o que pode ser visto fortemente no período de surgimento do Serviço Social no Brasil e até mesmo nos dias de hoje, em meio a práticas extremamente conservadoras), como pode servir à construção de um novo projeto societário que busque a consolidação de uma sociedade mais justa e igualitária.

Como apontam os princípios fundamentais do Código de Ética Profissional de 1993, o assistente social deve optar pela adoção de um projeto profissional vinculado ao processo de construção de uma nova ordem societária.

Portanto, a dimensão educativa da ação profissional pode vir a aten der as necessidades básicas do capital, contribuindo para a manutenção da atual ordem econômica. No entanto, pode também constituir um espaço político que possibilite o questionamento e a transformação societária.

A complexificação das expressões da quest ão social requer dos profissionais o uso de diferentes e criativas estratégias que possam contribuir para o alcance dos objetivos profissionais. Apesar do grande estranhamento de profissionais e acadêmicos quanto à relação "Arte e Serviço Social", esta se encontra presente cotidianamente nos mais variados aparatos institucionais e, principalmente, naqueles onde os profissionais visam à informação, socialização, humanização e emancipação dos sujeitos. Essa relação fica evidente não só no espaço profissional, mas também nos espaços acadêmicos, quando, mesmo que de forma discreta, a arte permeia as relações profissionais, sem dúvida como um importante instrumento de intervenção profissional para a emancipação e a liberdade. 


\section{Referências}

ABREU M. M. A. dimensão pedagógica do Serviço Social: bases histórico-conceituais e expressões particulares na sociedade brasileira. Serviço Social e Sociedade, São Paulo, n. 79, p. 43-71, 2004. Especial.

BARROSO M. L.; KARMANN L. F. A instituição Serviço social no contexto da lu ta pela hegemonia. Serviço Social e Sociedade, São Paulo, n.11, p.63-81, 1983.

BUTTIGIEG, J. A. Educação e hegemonia. In: COUTINHO, C. N. ; TEIXEIRA, A. P.(Org.). Ler Gramsci, entender a realidade. Rio de Janeiro: Civilização Brasileira, 2003. p. 39-50.

CAVALCANTE, T. L. Reflexões sobre o ensino e sua repercussão no Serviço Social . Serviço Social e Sociedade, São Paul, n.15, p.44-64, 1984.

CONSELHO FEDERAL DE SERVIÇO SOCIAL (CFESS). Código de Ética do Assistente Social: Coletânea de Leis e resoluções. 4. ed. Rio de Janeiro: CRESS 7ạ Região, 2005.

FISCHER, E. A necessidade da arte. 9. ed. Rio de janeiro: Guanabara, 1987.

FORTI, V. L. Serviço social, com arte... Em pauta, Rio de Janeiro, 12, p.205-210, 1998.

GRAMSCI, A. Cadernos do Cárcere. Rio de Janeiro: Civilização Brasileira, 1999.

GUERRA.Y. Instrumentalidade do processo de trabalho e serviço social. Serviço Social e Sociedade, São Paulo, n. 62, p. 6-34, 2000.

IAMAMOTO, M. V. Serviço Social na contemporaneidade : trabalho e formação profissional. 9. ed. São Paulo: Cortez, 2005.

IAMAMOTO, M.V.; CARVALHO R. Relações sociais e Serviço Social no Brasil : esboço de uma interpretação histórico-metodológica. 16 ed. São Paulo: Cortez, 2004.

JESUS, A. T. Educação e hegemonia: no pensamento de Antônio Gramsci. São Paulo: Cortez, 1989.

LEANDRO. Serviço Social e a Sétima Arte, acadêmicos e afins: textos acadêmicos, políticos, teóricos, filosóficos e de Serviço Social . Disponível em:

http://academicobifinho.blogspot.com/2006/10/servio -social-e-stima-arte.html. Acesso em: 16 out 2007.

MONTEIRO, J. M.; TEIXEIRA, T. M. Teatro e Serviço social: 20 anos depois. Rio de Janeiro: SESC-Tijuca, 1997.

PEIXOTO, M. I. H. Arte e grande público: a distância a ser extinta. São Paulo: Autores Associados, 2003. 
PRATES, J. C. A arte como matéria-prima e instrumento de trabalho para o assistente social. Disponível em:

http://revistaseletronicas.pucrs.br/teo/ojs/index.php/fass/article/viewFile/2313/1806. Acesso em: 7 jul. 2008.

RUMMERT, S. M. Os meios de comunicação de massa como aparelhos de hegemonia . 1986. Dissertação (Mestrado) - Instituto de Estudos Avançados em Educação,Fundação Getúlio Vargas, Rio de Janeiro.

SARMENTO H. B. Serviço Social, das tradicionais formas de regulação sociopolítica ao redimensionamento de suas funções sociais. UNIVERSIDADE DE BRASÍLIA. Cadernos Capacitação em Serviço Social e Política Social. Brasília: CEAD, 2000. Mod. 4. p. 95-110

SILVA, C. S. Arte na Saúde: instrumento de trabalho do Serviço Social. 2000. Trabalho de Conclusão de Curso (Graduação em Serviço Social) - Universidade Federal Fluminense, Rio de Janeiro.

SOUZA, T. P. Música e idoso: uma proposta de intervenção do Serviço social com arte. 2005. Dissertação (Mestrado) - Pontifícia Universidade Católica do Rio de Janeiro, Rio de Janeiro. 